\title{
Proline-Rich Acidic Protein 1 (PRAP1) is a Target of ARID1A and PGR in the Murine Uterus
}

\author{
Tae Hoon Kim and ${ }^{\dagger}$ Jae-Wook Jeong \\ Dept. of Obstetrics, Gynecology \& Reproductive Biology, Michigan State University College of Human Medicine, \\ Grand Rapids, MI 49503, USA
}

\begin{abstract}
ARID1A and PGR plays an important role in embryo implantation and decidualization during early pregnancy. Uterine specific Aridla knockout $\left(\mathrm{Pgr}^{\mathrm{cre} /+}\right.$ Aridla $\left.{ }^{f f}\right)$ mice exhibit in non-receptive endometrium at day 3.5 of gestation (GD 3.5). In previous studies, using transcriptomic analysis in the uterus of $\mathrm{Pgr}^{\mathrm{cre} / \mathrm{t}}$ Aridla ${ }^{\mathrm{fff}}$ mice, we identified proline-rich acidic protein $1(P R A P 1)$ as one of the down-regulated genes by ARID1A in the uterus. In the present study, we performed RTqPCR and immunohistochemistry analysis to investigate the regulation of PRAP1 by ARID1A and determine expression patterns of PRAP1 in the uterus during early pregnancy. During early pregnancy, PRAP1 expression was strong at day 0.5 of gestation (GD 0.5) and then decreased at GD 3.5 in the epithelium and stroma. After implantation, PRAP1 expression was remarkably reduced in the uterus. However, the expression of PRAP1 at GD 3.5 was remarkably increased in the $\mathrm{Pgr}^{\mathrm{cre} / \mathrm{A}} \mathrm{Aridl} \mathrm{aff}^{\mathrm{ff}}$ mice. To determine the ovarian steroid hormone regulation of PRAP1, we examined the expression of PRAP1 in ovariectomized control, $\mathrm{Pgr}^{\mathrm{cre} / \mathrm{H}}$ Aridla ${ }^{f f f}$, and progesterone receptor knock-out (PRKO) mice treated with progesterone. While PRAP1 proteins were strongly expressed in the luminal and glandular epithelium of control mice treated with vehicle, progesterone treatment suppressed the expression of PRAP1. However, PRAP1 was not suppressed in both the $\mathrm{Pgr}^{\mathrm{cre} / \mathrm{A}} \mathrm{Arid}^{\mathrm{i}} \mathrm{a}^{\mathrm{fff}}$ and PRKO mice compared to controls. Our results identified PRAP1 as a novel target of ARID1A and PGR in the murine uterus.
\end{abstract}

Key words : ARID1A, Uterus, Implantation, Progesterone, Estrogen, PRAP1

\section{INTRODUCTION}

The primary function of the uterus is supporting fertility, and the endometrium is the layer critically involved in receiving an embryo, facilitating implantation and decidualization, and supporting embryo growth and development until placentation (Marquardt et al., 2019). The uterus is a target tissue of ovarian steroid hormones. Estradiol (E2) stimulates endometrial proliferation and growth, while progesterone (P4) suppresses E2 induced epithelial cell proliferation, concomitant with initiation of stromal cell differentiation (Marquardt et al., 2019). These dynamic changes are necessary for embryo implantation and successful pregnancy (Tabibzadeh, 1998). The endometrium undergoes well-defined and regulated gene expression in preparation for implantation (Fox et al., 2016).

The physiological effects of $\mathrm{P} 4$ are mediated by the progesterone receptor (PGR). P4 and PGR together play a central role in reproductive events associated with the establishment and maintenance of pregnancy. PGR regulates implantation, decidualization, and glandular development via a complex paracrine signaling network (Wetendorf \&

\footnotetext{
Manuscript received July 26, 2019, Received in revised form August 13, 2019, Accepted September 5, 2019

${ }^{\dagger}$ Corresponding Author : Jae-Wook Jeong, Ph.D., Dept. of Obstetrics, Gynecology \& Reproductive Biology, Michigan State University College of Human Medicine, Grand Rapids, MI 49503, USA. Tel: +1-616-234-0987, Fax: +1-616-234-2733, E-mail: jeongj@ msu.edu
}

This is an Open Access article distributed under the terms of the Creative Commons Attribution Non-Commercial License (http:// creative-commons.org/licenses/by-nc/3.0) which permits unrestricted non-commercial use, distribution, and reproduction in any medium, provided the original work is properly cited. 
DeMayo, 2014; Adams \& DeMayo, 2015; Bhurke et al., 2016). The pivotal role of PGR within reproductive tissues causes it to be an area of focus within reproductive diseases (Teasley et al., 2018). Specifically, reduced expression of PGR has been associated with endometriosis, a prevalent disease in women's health (Grandi et al., 2017). Overall, aberrations of steroid hormone signaling can be found in many uterine disorders including infertility, endometriosis, endometrial cancer, and uterine leiomyoma (Han \& O'Malley, 2014; Islam et al., 2017; Patel et al., 2017; Yoo et al., 2017).

AT-rich interaction domain 1a (ARID1A) is one subunit within the SWItch/Sucrose Non-Fermentable (SWI/SNF) chromatin remodeling complex (Chunder et al., 2003). It is located in chromosomal region $1 \mathrm{p} 36$, which is a region that is often deleted within many different forms of cancer (Chunder et al., 2003; Takeda et al., 2016). A high frequency of mutation of ARID1A in cancers, specifically endometrioid cancer of the uterus and ovarian clear cell and endometrioid cancer, has revealed the potential of ARID1A to be defined as a tumor suppressor (Jones et al., 2010; Guan et al., 2011a). ARID1A is able to inhibit tumor growth and cellular proliferation (Guan et al., 2011b). Several studies have linked SWI/SNF and ARID1A to transcriptional regulation, particularly nuclear hormone-induced transcription and expression of cell cycle regulators (Mao \& Shih, 2013; Samartzis et al., 2013; Wu \& Roberts, 2013). Previously, we have shown that ARID1A protein levels are lower during both the proliferative and secretory phases, in epithelial and stromal cells of women with endometriosis compared to those without (Kim et al., 2015). Ablation of Aridla in the murine uterus results in the inability to inhibit E2-induced epithelial cell proliferation and E2-responsive target gene expression (Kim et al., 2015). However, the molecular mechanism of ARID1A action in steroid hormone regulation and pregnancy is not well studied.

Proline-rich acidic protein 1 (PRAP1) is a secretory protein of 149 amino acids, with a 20 amino acid signal peptide at its N-terminal. PRAP1 has been identified as a differentially expressed gene in the pregnant uterus of rodents (Kasik \& Rice, 1997). It is strongly expressed in the late pregnant uterus but disappears from the uterus within 3 days after birth (Kasik \& Rice, 1997). Human PRAPI mRNA is detected in the gastrointestinal tract, liver, and kidney. PRAP1 is localized in the epithelial lining of the colon and cervix, the hepatocytes, and the kidney proximal and distal tubules (Zhang et al., 2003). PRAP1 plays an important role in maintaining normal growth homeostasis in epithelia (Lanemo Myhrinder et al., 2008; Zhang et al., 2003). PRAP1 is a p53-responsive gene induced by genotoxic stress (Huang et al., 2012). It is an interacting partner of MAD1 and has a suppressive role in mitotic checkpoint signaling in hepatocellular carcinoma (Sze et al., 2014). Prapl mRNA is highly expressed in the uterine luminal epithelium of gestation day (GD) 0.5 in mice, disappears in the preimplantation day 3.5 uterus, and reappears abundantly in the luminal epithelium after embryo implantation (Diao et al., 2010). Therefore, PRAP1 is suggested as a marker for successful embryo implantation (Diao et al., 2010).

While Prap1 is up-regulated by E2, it is down-regulated by P4 (Diao et al., 2010; Xiong et al., 2011). However, the regulation of PRAP1 in the uterus is still elusive. In order to explore the regulation of PRAP1 expression in the uterus, we investigated the expression of PRAP1 in the uterus of Pgr knockout (PRKO) and uterine specific Aridla knockout $\left(\right.$ Pgr $^{\text {crel+ }}$ Aridla ${ }^{f f} ;$ Aridla $\left.{ }^{d / d}\right)$ mice. We also evaluated the regulation of PRAP1 in response to steroid hormones in the uterus.

\section{MATERIALS AND METHODS}

\section{Animals and tissue collection}

All mouse experiments were approved by the Institutional Animal Care and Use Committee of Michigan State University (IACUC number: 11/16-192-00). For the uteri 
samples during early pregnancy, wild C57BL/6 female mice at 8 weeks of age were individually mated with wildtype male mice and uteri were collected at different time points of pregnancy. The initiation of pregnancy was marked by the presence of the postcoital vaginal plug as day 0.5 of gestation (GD 0.5) for early pregnancy study. In order to investigate the expression of PRAP1 by PGR and ARID1A in the uterus, we used PRKO and Aridla ${ }^{d / d}$ mice (Lydon et al., 1995; Kim et al., 2015). We previously generated mice with conditional ablation of Aridla in the PGR positive cells (Aridla $a^{d / d}$ ) to study the role of Aridla in the uterus (Kim et al., 2015). Uterine tissues were collected from both horns then were stored at $-80^{\circ} \mathrm{C}$ for RNA or fixed in 4\% paraformaldehyde (vol/vol) and paraffin embedded.

To study PRAP1 expression by steroid hormone regulation, wild-type C57BL/6 mice, Aridla $a^{d / d}$ or PRKO mice at 6 weeks of age underwent bilateral ovariectomy. After at least 2 weeks to eliminate endogenous ovarian hormone completely, the mice were given subcutaneous injection with vehicle (sesame oil) or P4 (1mg/mouse) ( $n=3$ per genotype per treatment). The uteri were collected at 6 hours after the steroid hormone injection.

\section{RNA isolation and quantitative real-time PCR}

Total RNA was isolated from uteri using Qiagen RNeasy total RNA isolation kit (Qiagen, Valencia, CA, USA). The expression levels of Prapl were quantified by RT-qPCR using an Applied Biosystems StepOnePlus system according to the manufacturer's instructions (Applied Biosystem, Foster City, CA, USA). The cDNAs were synthesized with MMLV Reverse Transcriptase (Invitrogen, Carlsbad, CA, USA) by the use of $1 \mu \mathrm{g}$ of total RNA primed with random hexamer primers according to the manufacturer's instructions. RT-qPCR was performed on cDNA to assess the expression levels of genes of interest with primers, by using SYBR green and 96-well optical plates, with an Applied Biosystems StepOnePlus (Applied Biosystem, Foster City, CA, USA). Experimental Prapl data were normalized to
18S ribosomal RNA. Analysis of Prapl mRNA expression was first undertaken by the standard curve method, and results were corroborated by $\mathrm{CT}$ values assessing levels of gene expression. All data are presented as mean \pm SEM. Statistical analyses were performed using Student's $t$-tests using the Instat package from GraphPad (San Diego, CA, USA). $p<0.05$ was considered statistically significant.

\section{Immunohistochemistry}

Uterine sections of $5 \mu \mathrm{m}$ thickness were blocked with $10 \%$ normal goat serum in PBS ( $\mathrm{pH} 7.5)$ for immunohistochemistry. Sections were exposed to primary anti-PRAP1 (HPA038713, Sigma-Aldrich, St. Louis, MO, USA) antibody in $10 \%$ normal goat serum in PBS ( $\mathrm{pH} \mathrm{7.5)} \mathrm{overnight} \mathrm{at}$ $4^{\circ} \mathrm{C}$. The Sections were incubated with biotinylated goat anti-rabbit 2nd antibody (BA-1000; Vector Laboratories, Burlingame, CA, USA). Following exposure to the horseradish peroxidase-conjugated streptavidin substrate, positive immunoreactivity (brown precipitate) was detected using the Vectastain Elite DAB kit (Vector Laboratories, Burlingame, CA, USA) and hematoxylin (Biocare Medical, Pacheco, CA, USA) were used for a nuclear counterstain.

\section{RESULTS}

\section{PRAP1 is a target of ARID1A in the murine uterus}

ARID1A has a critical role in modulating epithelial proliferation at the pre-implantation stage which is a critical requisite for uterine receptivity (Kim et al., 2015). To determine transcriptional regulation of Prapl by ARID1A, RT-qPCR was performed in the uteri of control (Aridla ${ }^{f / f}$ ) and $\mathrm{Pgr}^{\mathrm{cre} /+}$ Aridla ${ }^{f / f}$ (Aridla ${ }^{\mathrm{d} / d}$ ) mice (Kim et al., 2015) at GD 3.5. The results revealed that there was a significant increase in Prapl mRNA expression in the Aridla ${ }^{d / d}$ mice uterus compared to the control mice (Fig. 1A). This result was extended through immunohistochemistry to examine spatial expression of PRAP1 protein in the Aridla ${ }^{d / d}$ mice (Fig. 1B). Control samples at GD 3.5 showed very weak 


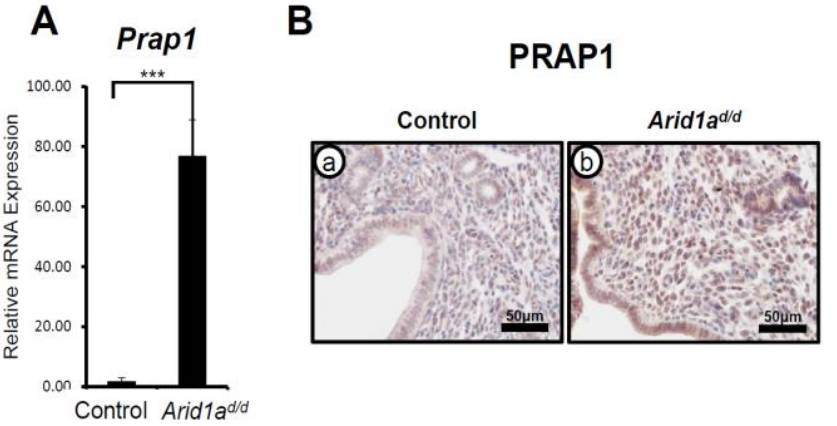

Fig. 1. The expression of PRAP1 in the uteri of control, Arid1 $^{d / d}$, and PRKO mice. (A) The expression pattern of Prap1 from control and Aridla ${ }^{d / d}$ mice uteri determined by RT-qPCR. Total RNA used for RT-qPCR assay was prepared from control and Arid $1 a^{d / d}$ mice uteri at GD 3.5. The results represent the mean \pm SEM of three independent RNA sets. $p<0.05$. (B) The localization pattern of PRAP1 proteins by immunohistochemistry in the uteri of control (a) and Aridl $a^{d / d}$ (b) mice. Uterine sections were collected from control and Aridla $a^{d / d}$ mice at GD 3.5. PRAP1, proline-rich acidic protein 1; GD, day of gestation.
PRAP1 expression within the uterine epithelial, glandular, and stromal cells. However, Aridla ${ }^{d / d}$ mice showed a remarkable increase in PRAP1 expression throughout when compared to control mice. These data suggest that the expression of PRAP1 is suppressed by ARID1A.

\section{The expression of PRAP1 in the uterus during} early pregnancy

The expression of ARID1A mRNA and protein was strongly detected on GD 0.5 , which consistently expressed until GD 6.5 in the uterus (Kim et al., 2015). To investigate the expression pattern of PRAP1 in mouse uteri during early pregnancy, we performed immunohistochemistry from GD 0.5 to GD 7.5 in the uteri of natural pregnancy (Fig. 2). The initiation of pregnancy was marked by the presence of the postcoital vaginal plug (GD 0.5). At GD 0.5, PRAP1 expression was present within uterine luminal and glandular epithelium, however expression was not seen within stroma. At GD 2.5, expression increased, and was also present
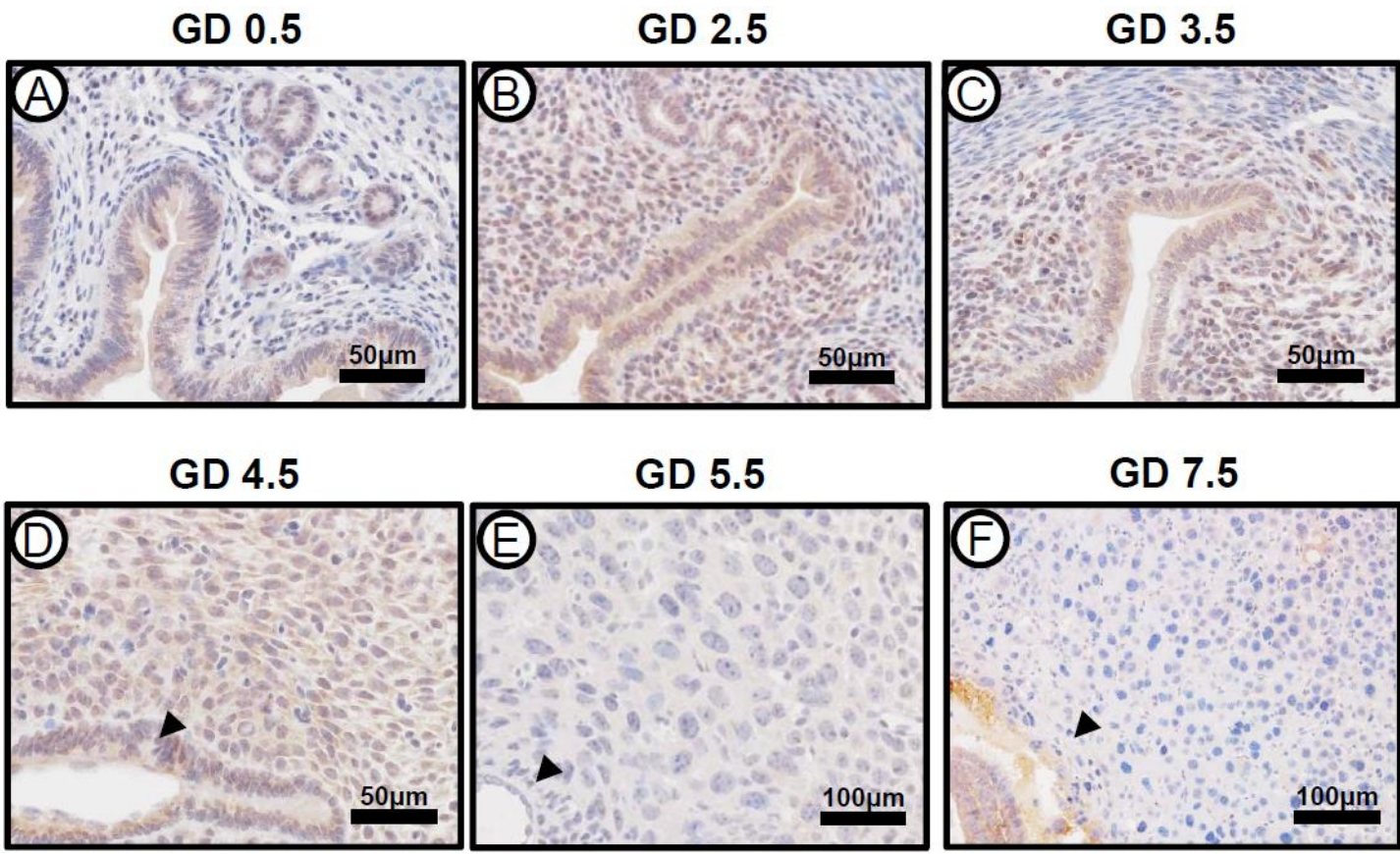

GD 5.5

GD 7.5
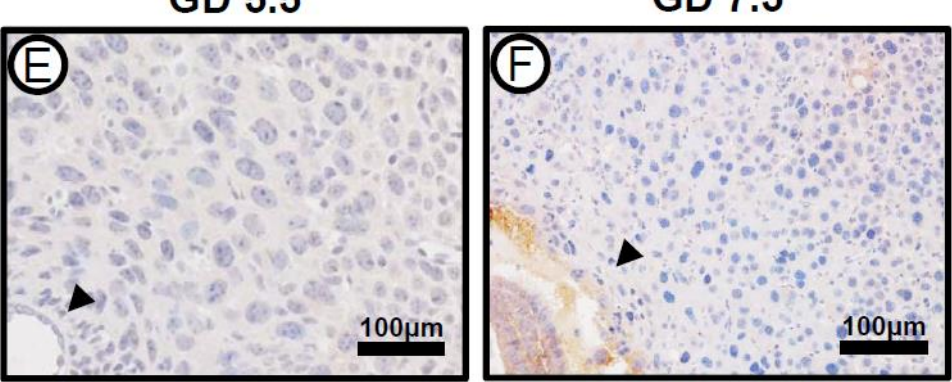

Fig. 2. The localization pattern of PRAP1 during early pregnancy. Representative photomicrographs show immunohistochemical staining of PRAP1 proteins in the uterus from GD 0.5 to GD 7.5. The arrow indicates the embryo. PRAP1, proline-rich acidic protein 1; GD, day of gestation. 
within stroma. At GD 3.5 and 4.5, PRAP1 levels showed a slight decrease in uterine epithelial and stromal cells. Interestingly, the expression of PRAP1 was remarkably decreased after embryo implantation GD 5.5 and 7.5. The expression of PRAP1 was not observed in the uterus including the primary and secondary decidual zone at GD 5.5 and 7.5. These data indicate that PRAP1 is tightly regulated in the uterus during early pregnancy.

\section{The regulation of PRAP1 by P4 in the uterus}

In order to evaluate PRAP1 expression in response to $\mathrm{P} 4$ treatment, immunohistochemistry was performed on ovariectomized control (wild type and Aridla ${ }^{\text {f/f }}$ ), Aridla ${ }^{d / d}$, and PRKO mice treated with either vehicle or P4 for 6 hours (Fig. 3). PRAP1 expression was strongly detected at luminal and glandular epithelium of the ovariectomized control mice treated with vehicle. After P4 treatment, the strong PRAP1 expression disappeared at the luminal and glandular epithelium of control mice. Both Aridla d/d and the PRKO mice showed expression of PRAP1 after vehicle treatment. However, PRAP1 expression was not changed in Aridla ${ }^{d / d}$ and PRKO mice after P4 treatment. This data further reveals that PRAP1 is regulated by PGR and ARID1A.

\section{DISCUSSION}

Our study examined the regulation of Prapl by ARID1A and determined the expression patterns of PRAP1 in the uterus during early pregnancy and in response to ovarian steroid hormone treatment. In the present study, we report that PRAP1 expression levels are remarkably increased in mice with conditional ablation of Aridla (Aridla ${ }^{d / d}$ ) (Fig. 1). ARID1A plays a role as a transcriptional repressor in breast cancer (Guo et al., 2018). Loss of ARID1A profoundly alters histone modifications and the transcriptome. In response to a lack of Aridla, mice did not suppress the expression of PRAP1 by P4, further confirming ARID1A
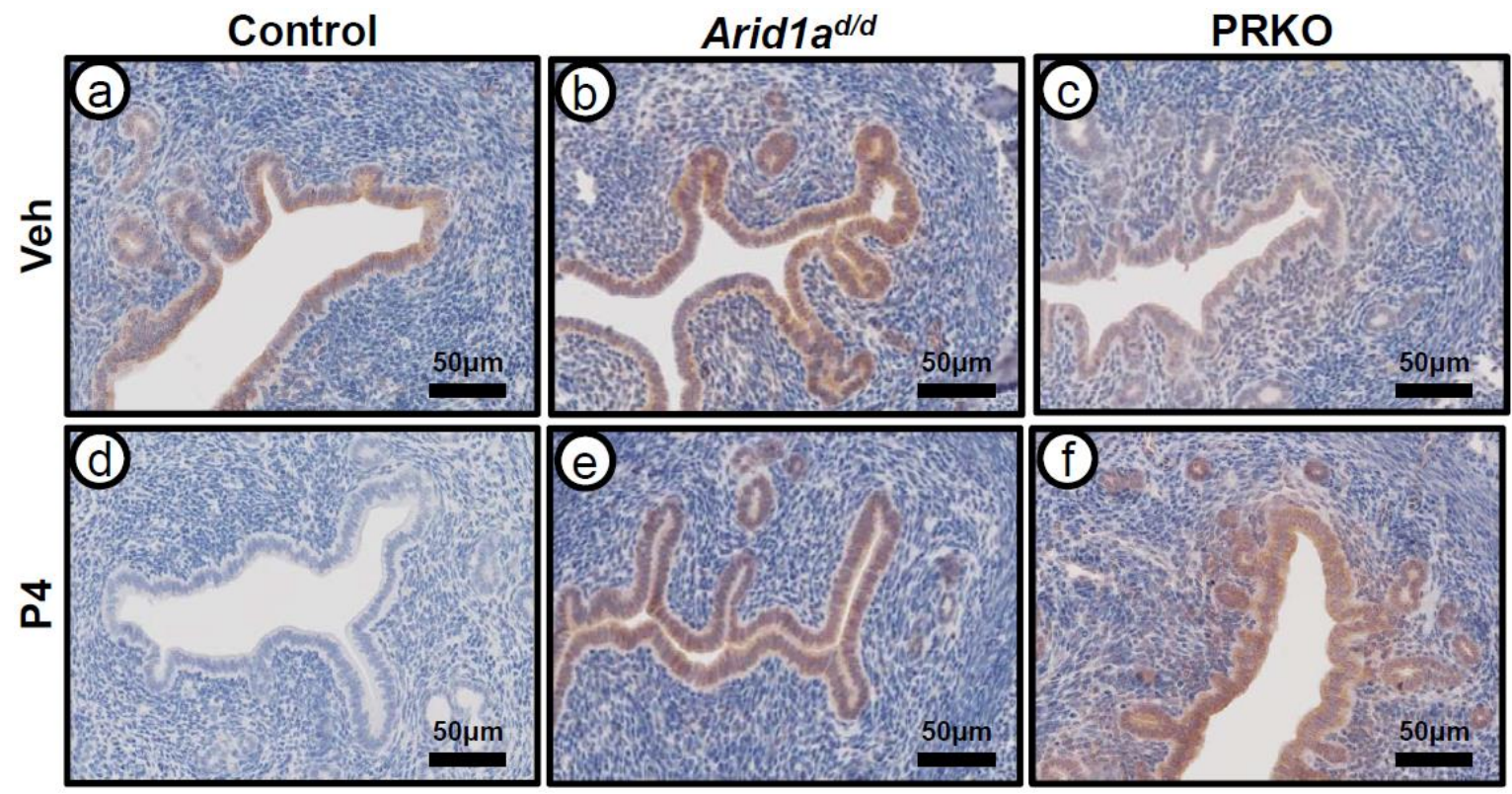

Fig. 3. The regulation of PRAP1 expression by ARID1A and PGR in the uterus. Representative photomicrographs show the localization pattern of PRAP1 by immunohistochemistry in the vehicle or P4-treated uteri from control (a and d), Aridla ${ }^{d / d}$ (b and e), and PRKO (c and f). Uterine sections were collected from ovariectomized control, Aridla $^{d / d}$, and PRKO that were treated with vehicle (sesame oil; a-c) or P4 (d-f) for 6 hours. PRAP1, proline-rich acidic protein 1; PRKO, progesterone receptor knock-out. 
is a transcriptional suppressor of Prapl gene.

Throughout implantation and early pregnancy, fluctuations in steroid hormone expression are exhibited. GD 0.5 and 1.5 in murine pregnancy are the days in which preovulatory ovarian E2 is secreted, and proliferation occurs. From GD 2.5 on, proliferation shifts from the luminal and glandular epithelial cells to the stromal cells. Overall, we observed fluctuation of PRAP1 expression (Fig. 2). At GD 2.5 expression levels were the highest overall. E2 stimulated proliferation occurs during the first two days of pregnancy in the mouse uterus (Das, 2010). Our result is consistent that PRAP1 is regulated by E2 (Xiong et al., 2011). At GD 4.5, implantation occurs, as stromal cells transition into decidual cells in response to a blastocyst (Huet-Hudson et al., 1989). We and others showed reduction of PRAP1 expression after implantation and down-regulation by P4 (Diao et al., 2010; Xiong et al., 2011). The invading blastocyst then induces a decidualization reaction of the P4-primed stromal cells, where they differentiate into morphologically and functionally unique cells to surround the implanting embryo and support growth until placentation, all under critical continued $\mathrm{P} 4$ regulation (Marquardt et al., 2019). Therefore, PRAP1 is a suppressed protein at the post-implantation stage.

PRKO is an invaluable model in assessing P4's role in gene and protein expression. Past research has revealed that the ablation of PGR results in abnormalities in the reproductive biology of the mouse and also a defect in the implantation process (Vasquez \& DeMayo, 2013). Within this study, we utilized the PRKO mouse model in order to analyze the expression of PRAP1 in response to the ablation of both PGR isoforms (Fig. 3). Results showed a difference in only epithelial expression of PRAP1 in the PRKO mouse model in comparison to controls. Epithelial cells are associated with the production of paracrine factors, mediated through the PGR receptors, which are critical in enhancing epithelial differentiation and growth within the uterus (Lee et al., 2006; Franco et al., 2012). These results suggest that epithelial PRAP1 expression is regulated by PGR.

P4 is a steroid hormone that is critical in reproductive processes, and has been utilized for therapeutic treatment in peri-menopausal women who experience aberrant bleeding or menstrual problems (Prior, 2011; Czyzyk et al., 2017). In order to analyze P4's effect on PRAP1 expression, we examined PRAP1 expression within control, Aridla d/d, and PRKO mice, with both vehicle and 6-hour P4 treatment (Fig. 3). In this analysis we found that P4 treatment decreased expression in the control mice. This result allows us to hypothesize P4's role in PRAP1 expression, and also allows for a connection of P4 treatment in the two different mouse models. P4 does not suppressed PRAP1 expression in the Aridla ${ }^{d / d}$ mice. PRAP1 plays normal epithelial cell homeostasis as a negative regulator and the down-regulation of Prapl in cancer cells may lead to dysregulated cell growth (Zhang et al., 2003). Although the regulation of PRAP1 expression by ovarian steroid hormone suggests a possible connection to uterine function, molecular mechanisms of PRAP1 regulation should be dissected in uterine function during early pregnancy.

Our results demonstrate that PRAP1 is a novel target of ARID1A and PGR in the murine uterus. Additional research within this context would provide for greater insight into the role of PRAP1 within the context of reproductive biology, and provide for a new possible therapeutic target for uterine disorders.

\section{CONFLICT OF INTERESTS}

The authors declare no potential conflict of interest.

\section{REFERENCES}

Adams NR, DeMayo FJ (2015) The role of steroid hormone receptors in the establishment of pregnancy in rodents. Adv Anat Embryol Cell Biol 216:27-49. 
Bhurke AS, Bagchi IC, Bagchi MK (2016) Progesteroneregulated endometrial factors controlling implantation. Am J Reprod Immunol 75:237-245.

Chunder N, Mandal S, Basu D, Roy A, Roychoudhury S, Panda CK (2003) Deletion mapping of chromosome 1 in early onset and late onset breast tumors: A comparative study in eastern India. Pathol Res Pract 199:313321.

Czyzyk A, Podfigurna A, Genazzani AR, Meczekalski B (2017) The role of progesterone therapy in early pregnancy: From physiological role to therapeutic utility. Gynecol Endocrinol 33:421-424.

Das SK (2010) Regional development of uterine decidualization: Molecular signaling by Hoxa-10. Mol Reprod Dev 77:387-396.

Diao H, Xiao S, Zhao F, Ye X (2010) Uterine luminal epithelium-specific proline-rich acidic protein 1 (PRAP1) as a marker for successful embryo implantation. Fertil Steril 94:2808-2811.

Fox C, Morin S, Jeong JW, Scott RT Jr, Lessey BA (2016) Local and systemic factors and implantation: What is the evidence? Fertil Steril 105:873-884.

Franco HL, Rubel CA, Large MJ, Wetendorf M, FernandezValdivia R, Jeong JW, Spencer TE, Behringer RR, Lydon JP, Demayo FJ (2012) Epithelial progesterone receptor exhibits pleiotropic roles in uterine development and function. FASEB J 26:1218-1227.

Grandi G, Mueller MD, Bersinger NA, Facchinetti F, McKinnon BD (2017) The association between progestins, nuclear receptors expression and inflammation in endometrial stromal cells from women with endometriosis. Gynecol Endocrinol 33:712-715.

Guan B, Mao TL, Panuganti PK, Kuhn E, Kurman RJ, Maeda D, Chen E, Jeng YM, Wang TL, Shih IeM (2011a) Mutation and loss of expression of ARID1A in uterine low-grade endometrioid carcinoma. Am J Surg Pathol 35:625-632.

Guan B, Wang TL, Shih IeM (2011b) ARID1A, a factor that promotes formation of SWI/SNF-mediated chromatin remodeling, is a tumor suppressor in gynecologic cancers. Cancer Res 71:6718-6727.

Guo X, Zhang Y, Mayakonda A, Madan V, Ding LW, Lin LH, Zia S, Gery S, Tyner JW, Zhou W, Yin D, Lin DC, Koeffler HP (2018) ARID1A and CEBPalpha cooperatively inhibit UCA1 transcription in breast cancer. Oncogene 37:5939-5951.

Han SJ, O'Malley BW (2014) The dynamics of nuclear receptors and nuclear receptor coregulators in the pathogenesis of endometriosis. Human Reprod Update 20:467-484.

Huang BH, Zhuo JL, Leung CH, Lu GD, Liu JJ, Yap CT, Hooi SC (2012) PRAP1 is a novel executor of p53dependent mechanisms in cell survival after DNA damage. Cell Death Dis 3:e442.

Huet-Hudson YM, Andrews GK, Dey SK (1989) Cell typespecific localization of c-myc protein in the mouse uterus: Modulation by steroid hormones and analysis of the periimplantation period. Endocrinology 125 : 1683-1690.

Islam MS, Ciavattini A, Petraglia F, Castellucci M, Ciarmela P (2017) Extracellular matrix in uterine leiomyoma pathogenesis: A potential target for future therapeutics. Human Reprod Update 24:59-85.

Jones S, Wang TL, Shih IeM, Mao TL, Nakayama K, Roden R, Glas R, Slamon D, Diaz LA Jr, Vogelstein B, Kinzler KW, Velculescu VE, Papadopoulos N (2010) Frequent mutations of chromatin remodeling gene ARID1A in ovarian clear cell carcinoma. Science 330: 228-231.

Kasik J, Rice E (1997) A novel complementary deoxyribonucleic acid is abundantly and specifically expressed in the uterus during pregnancy. Am J Obstet Gynecol $176: 452-456$.

Kim TH, Yoo JY, Wang Z, Lydon JP, Khatri S, Hawkins SM, Leach RE, Fazleabas AT, Young SL, Lessey BA, $\mathrm{Ku}$ BJ, Jeong JW (2015) ARID1A is essential for 
endometrial function during early pregnancy. PLOS Genet 11:e1005537.

Lanemo Myhrinder A, Hellqvist E, Sidorova E, Soderberg A, Baxendale H, Dahle C, Willander K, Tobin G, Backman E, Soderberg O, Rosenquist R, Horkko S, Rosen A (2008) A new perspective: Molecular motifs on oxidized LDL, apoptotic cells, and bacteria are targets for chronic lymphocytic leukemia antibodies. Blood 111:3838-3848.

Lee K, Jeong J, Tsai MJ, Tsai S, Lydon JP, DeMayo FJ (2006) Molecular mechanisms involved in progesterone receptor regulation of uterine function. J Steroid Biochem Mol Biol 102:41-50.

Lydon JP, DeMayo FJ, Funk CR, Mani SK, Hughes AR, Montgomery CA Jr, Shyamala G, Conneely OM, O'Malley BW (1995) Mice lacking progesterone receptor exhibit pleiotropic reproductive abnormalities. Genes Dev 9:2266-2278.

Mao TL, Shih IeM (2013) The roles of ARID1A in gynecologic cancer. J Gynecol Oncol 24:376-381.

Marquardt RM, Kim TH, Shin JH, Jeong JW (2019) Progesterone and estrogen signaling in the endometrium: What goes wrong in endometriosis? Int J Mol Sci 20:3822.

Patel BG, Rudnicki M, Yu J, Shu Y, Taylor RN (2017) Progesterone resistance in endometriosis: Origins, consequences and interventions. Acta Obstet Gynecol Scand 96:623-632.

Prior JC (2011) Progesterone for symptomatic perimenopause treatment: Progesterone politics, physiology and potential for perimenopause. Facts Views Vis Obgyn 3:109-120.

Samartzis EP, Noske A, Dedes KJ, Fink D, Imesch P (2013) ARID1A mutations and PI3K/AKT pathway alterations in endometriosis and endometriosis-associated ovarian carcinomas. Int J Mol Sci 14:18824-18849.

Sze KM, Chu GK, Mak QH, Lee JM, Ng IO (2014)
Proline-rich acidic protein 1 (PRAP1) is a novel interacting partner of MAD1 and has a suppressive role in mitotic checkpoint signalling in hepatocellular carcinoma. J Pathol 233:51-60.

Tabibzadeh S (1998) Molecular control of the implantation window. Hum Reprod Update 4:465-471.

Takeda T, Banno K, Okawa R, Yanokura M, Iijima M, IrieKunitomi H, Nakamura K, Iida M, Adachi M, Umene K, Nogami Y, Masuda K, Kobayashi Y, Tominaga E, Aoki D (2016) ARID1A gene mutation in ovarian and endometrial cancers (Review). Oncol Rep 35:607-613.

Teasley HE, Chang HJ, Kim TH, Ku BJ, Jeong JW (2018) Expression of PIK3IP1 in the murine uterus during early pregnancy. Biochem Biophys Res Commun 495: 2553-2558.

Vasquez YM, DeMayo FJ (2013) Role of nuclear receptors in blastocyst implantation. Semin Cell Dev Biol 24: 724-735.

Wetendorf M, DeMayo FJ (2014) Progesterone receptor signaling in the initiation of pregnancy and preservation of a healthy uterus. Int J Dev Biol 58:95-106.

Wu JN, Roberts CW (2013) ARID1A mutations in cancer: Another epigenetic tumor suppressor? Cancer Discov 3:35-43.

Xiong GF, Zhang YS, Han BC, Chen W, Yang Y, Peng JP (2011) Estradiol-regulated proline-rich acid protein 1 is repressed by class I histone deacetylase and functions in peri-implantation mouse uterus. Mol Cell Endocrinol 331:23-33.

Yoo JY, Yang WS, Lee JH, Kim BG, Broaddus RR, Lim JM, Kim TH, Jeong JW (2017) MIG-6 negatively regulates STAT3 phosphorylation in uterine epithelial cells. Oncogene 37:255-262.

Zhang J, Wong H, Ramanan S, Cheong D, Leong A, Hooi SC (2003) The proline-rich acidic protein is epigenetically regulated and inhibits growth of cancer cell lines. Cancer Res 63:6658-6665. 